\title{
GESTÃO DE RECURSOS HÍDRICOS NA AMAZÔNIA: UM PANORAMA DA PARTICIPAÇÃO DA SOCIEDADE CIVIL NOS ESPAÇOS DELIBERATIVOS
}

\author{
F. N. FERREIRA ${ }^{1,}{ }^{*}$, H. M. C. RIBEIRO ${ }^{1}$, N. E. S. BELTRÃO ${ }^{1}$, A. N. PONTES ${ }^{1}$, S. R. M. LOPES $^{1}$ \\ ${ }^{1}$ Universidade do Estado do Pará \\ nanda_fnf@yahoo.com.br*
}

Submetido 03/11/2017 - Aceito 20/12/2017

DOI: $10.15628 /$ holos.2017.6505

\section{RESUMO}

O atual modelo de gestão hídrica no Brasil, inserido pela Lei $n$ o. 9.433/1997, foi um marco da governança hídrica no país ao prever a descentralização nas tomadas de decisão e proporcionar a participação dos diversos "stakeholders". Nesse sentido, a pesquisa objetivou investigar a efetividade da Política Nacional de Recursos Hídricos nos estados da Amazônia Legal sob o viés da participação da sociedade civil e do acesso à informação nos Conselhos Estaduais de Recursos Hídricos. Para tanto, realizou-se uma pesquisa descritiva e exploratória, mediante levantamento bibliográfico e documental, com análise de decretos de nomeação e atas de reunião para identificar o quantitativo de representantes dos diversos atores, bem como aplicouse uma estatística multivariada por meio do software Minitab 17 no tratamento de dados a fim de investigar as similaridades entre os estados. A pesquisa constatou que a efetivação da referida política pública de forma descentralizada nos estados brasileiros da Amazônia Legal ainda não ocorreu satisfatoriamente no que refere à promoção da participação da sociedade civil e ao acesso à informação, havendo a necessidade do investimento em educação ambiental e maior disponibilidade de informação e facilitação do seu acesso.

PALAVRAS-CHAVE: Governança, Política Nacional de Recursos Hídricos, Informação, Gestão descentralizada.

\section{WATER RESOURCES MANAGEMENT IN THE AMAZON: AN OVERVIEW OF CIVIL SOCIETY PARTICIPATION IN DELIBERATIVE SPACES}

\begin{abstract}
The current model of water management in Brazil, inserted by Law no. 9,433 / 1997, was a milestone in water governance in the country in predicting the decentralization of decision-making and the participation of the various stakeholders. In this sense, the research aimed to investigate the effectiveness of the National Water Resources Policy in the states of the Legal Amazon under the bias of civil society participation and access to information in the State Councils of Water Resources. For that, a descriptive and exploratory research was carried out, through a bibliographical and documentary survey, with analysis of appointment
\end{abstract}

decrees and meeting minutes to identify the quantitative representation of the different actors, as well as a multivariate statistic was applied through the software Minitab 17 in data processing to investigate the similarities between states. The research found that the implementation of this public policy in a decentralized way in the Brazilian states of the Legal Amazon has not yet occurred satisfactorily in what concerns the promotion of civil society participation and access to information, with the need for investment in environmental education and greater availability information and facilitation of their access.

KEYWORDS: Governance, National Policy on Water Resource, Information, Decentralized management. 


\section{INTRODUÇÃO}

Os usos diretos e indiretos da água pelos seres humanos ocasionam impactos cumulativos sobre o ciclo hidrológico que geram consequências locais e globais. A comunidade internacional, desde a Conferência da Água em Mar del Plata de 1977, percebia os desafios gerados pela complexidade da gestão da água e a necessidade de um modelo de gestão que expandisse a coordenação das decisões sobre o uso da água aos múltiplos atores. Contudo, a governança da água somente ganhou proeminência internacional e se solidificou em 2000, sob o lema denominado "tornando a água um problema de todos", tendo a governança a missão de superar as limitações dos modelos de gestão anteriores (Schmidt \& Matthews, 2017).

Aliado a isto, o processo de reconhecimento da água como um direito fundamental do ser humano pela comunidade internacional teve afirmação histórica na década de 1980, quando se iniciou a conscientização de que a poluição e o desperdício afetavam diretamente o bem-estar humano, especialmente pelos países em desenvolvimento (Aith \& Rothbarth, 2015). Paralelamente, no Brasil, vivenciava-se o ativismo dos movimentos sociais organizados, os quais se multiplicaram e fortaleceram-se a partir da ampliação dos espaços destinados ao exercício da democracia participativa na gestão estatal, inclusive na seara ambiental e de recursos hídricos, promovida pela Constituição Federal de 1988, o que permitiu a realização de mudanças na sociedade, como a conquista de direitos sociais, acesso a serviços urbanos, entre outros (Fonseca, Bursztyn, \& Moura, 2012).

A mobilização social foi fundamental para a luta contra a monopolização da gestão de recursos hídricos pelo setor energético, uma vez que à época só se dispunha do Código de Águas Brasileiro de 1934, o qual foi elaborado em um período cuja prioridade política do Brasil era a maior geração de energia elétrica em detrimento dos outros usos da água, pois o país estava em processo de industrialização (Buriti \& Barbosa, 2015). Contudo, a redemocratização política, advinda na década de 1980, oportunizou as políticas públicas de gestão a adotar composições paritárias entre sociedade civil e o Estado nos ambientes de democracia deliberativa (como nos conselhos gestores), oportunizando que as diversas formas de organizações de massa surgissem e pudessem influenciar direta ou indiretamente na gestão pública (Jacobi \& Barbi, 2007).

Nessa linha de ampliação da participação pública e de busca pela garantia do acesso e da disponibilidade hídrica para os múltiplos usos da água tanto às presentes quanto às futuras gerações, a Lei no. 9.433, de 8 de janeiro de 1997, que instituiu a Política Nacional de Recursos Hídricos - PNRH, previu que a gestão hídrica deveria ocorrer de forma descentralizada, compartilhada e com ampla participação de todos os interessados, possível de ser observada no inciso VI, artigo 10 (Matos \& Dias, 2013). No entanto, sabe-se que a multiplicação de espaços democráticos, por si só, não garante uma participação pública de qualidade, com pluralidade e equilíbrio, visto que o histórico de desigualdades na sociedade brasileira gerou reflexos negativos no processo de efetivação de princípios democráticos (Jacobi, Cibim, \& Leão, 2015).

A efetiva participação está diretamente vinculada à cidadania ambiental ativa, ou seja, à existência de sujeitos sociais capazes de perseguir os seus direitos ambientais (Machado, 2003a). Para tanto, três dos princípios do direito ambiental circundam esta realidade: a informação, a educação ambiental e a participação social, todos interligados (Santiago, 2012). Porquanto, não poderá haver a participação sem que a sociedade esteja devidamente informada e consciente 
quanto à importância da proteção do meio ambiente ecologicamente equilibrado como direito fundamental da pessoa humana (Alves, 2013).

Como se sabe, as formas de ocupação e do uso do solo, a expansão agrícola e o desenvolvimento industrial são vetores que refletem diretamente nos aspectos qualiquantitativos da água, requerendo um monitoramento constante dos corpos hídricos a fim de acompanhar a conservação deste recurso natural (Miranda, Pereira, Alves, \& Oliveira, 2009). Além disso, a promoção da gestão descentralizada no Brasil também está atrelada ao fato de que, apesar de ser um país com abundância hídrica, sofre com a distribuição irregular deste recurso cuja maior concentração está na região menos desenvolvida e antropizada: a região norte (Veiga \& Magrini, 2013).

Seguindo nesta vertente, a governança da água mostra-se como uma ferramenta essencial para aprimorar a sustentabilidade entre a oferta e a demanda por água a partir da participação ampla dos usuários dentro de uma bacia hidrográfica (Tundisi, 2008), o que será melhor abordado a seguir.

Nesse aspecto, a pesquisa teve como objetivo investigar a efetividade da Política Nacional de Recursos Hídricos (PNRH) nos rios amazônicos sob o viés da participação da sociedade civil e do acesso à informação, que estão associados ao conceito de governança da água. É importante justificar que a seleção desta área de estudo se deu pelo fato de a região amazônica deter a bacia hidrográfica com maior extensão do mundo, a bacia do Rio Amazonas, da qual 63\% encontra-se no Brasil (Val et al, 2010).

\section{A GOVERNANÇA NA GESTÃO AMBIENTAL E HÍDRICA}

Antes de traçar os caminhos da governança ambiental no Brasil até se chegar nos recursos hídricos, convém apresentar o seu conceito como sendo a busca por práticas que ampliem os mecanismos de democracia participativa de modo a permitir a mediação de relações entre representantes do governo, da sociedade civil e de agentes econômicos no processo decisório, destacando-se que esse exercício de gerir os recursos naturais levando em consideração a participação dos diversos usuários nas tomadas de decisão iniciou em meados da década de 1980 (Jacobi, Fracalanza, \& Silva-Sánchez, 2015). Anteriormente, a gestão hídrica era concentrada no Poder Público, e este, por sua vez, dava preferência aos interesses dos grandes usuários e empreendedores nas tomadas de decisão sobre o destino das águas, não havendo espaço para os pequenos usuários, muito menos para a sociedade, nos processos decisórios (Tucci, Hespanhol, \& Netto, 2001).

No que concerne à importância da governança hídrica, a instituição internacional Water Governance Facility acredita que é o mecanismo pelo qual se poderá determinar a equidade e a eficiência na alocação e distribuição dos recursos e serviços hídricos, bem como contribuirá para o balanço do uso da água entre as atividades socioeconômicas e ecossistêmicas (WGF, 2015). Para tanto, faz-se necessário que a governança seja aberta e transparente, inclusiva e comunicativa, coerente e integrada, equitativa e ética, eficiente, responsável e sustentável, com o objetivo de promover a responsabilidade coletiva e integrada de todos os atores (Camkin \& Neto, 2016). 
Em uma análise das normas legais hídricas sob o enfoque da história ambiental do Brasil, informa-se que o antecessor da PNRH foi o Código de Águas Brasileiro de 1934, o qual surgiu com a finalidade de proporcionar ao poder público o controle e o incentivo ao uso industrial dos corpos d'água (Buriti \& Barbosa, 2014). Salienta-se que o referido Código teve esta tendência por ter sido instituído em um contexto histórico de promoção à industrialização do país, no qual a prioridade da política era a maior geração de energia elétrica em detrimento de outros usos da água, além de a água ser vista como abundante e infinita, pois, à época, não havia relatos de problemas de escassez e poluição.

Devido à ausência no Código de Águas Brasileiro de proteção específica aos aspectos qualitativos e quantitativos da água e à inexistência de regulamentação dos seus demais usos surgidos com o desenvolvimento de novas atividades econômicas, o país começou a sentir os efeitos negativos do uso indiscriminado da água na metade do século XX: a escassez e a poluição (Granziera, 2000).

Como mencionado, no âmbito internacional, os debates acerca da construção do conceito de governança eram iniciados na década de 1980, e, influenciado por este movimento, o Brasil incorporou os primeiros fundamentos democráticos na legislação ambiental, inicialmente, com a Política Nacional do Meio Ambiente - PNMA (Lei no. 6.938/1981) (Wolkmer \& Pimmel, 2013).

Destacam-se três instrumentos da PNMA (artigo 9o): a garantia do direito à informação por parte do poder público, o relatório da qualidade ambiental e o Sistema Nacional de Informação sobre o Meio Ambiente - SNIMA, todos imprescindíveis à participação social, porquanto servirão para abastecer a sociedade com informações ambientais. Ademais, referida lei criou o Sistema Nacional de Meio Ambiente - SISNAMA, inserido na sua composição o Conselho Nacional de Meio Ambiente - CONAMA, no qual a sociedade tem acento. Portanto, de grande relevância a governança ambiental.

Há ainda mais três importantes instrumentos dessa política nos quais a participação da sociedade civil se faz necessária para o alcance do objetivo de compatibilizar o desenvolvimento econômico-social com a preservação da qualidade ambiental e equilíbrio ecológico são o zoneamento ambiental, a avaliação de impacto ambiental e o licenciamento ambiental (Coletti, 2012).

Posteriormente, a Constituição Federal, de 1988, veio reforçar os arranjos participativos ao prever espaços de deliberação com participação da sociedade civil como os conselhos gestores de políticas públicas, o orçamento participativo, o referendo, o plebiscito, etc. (JACOBI, 2003).

Em 1997, por meio da Lei №. 9.433/97, a política de gestão hídrica brasileira reconhece a necessidade da adoção de um sistema descentralizado, por bacia hidrográfica e com ampla participação integrada dos diversos atores que afetam ou são afetados pela referida política pública, os "stakeholders", de forma a proporcionar os múltiplos usos da água (Castro, Alvarenga, \& Júnior, 2005). Em outras palavras, os governantes, os usuários e, especialmente, a comunidade às proximidades de determinado corpo hídrico têm o direito de participar dos processos decisórios de forma democrática e equânime, emitindo opiniões e, principalmente, tendo os seus valores e demandas sociais refletidos nos marcos normativos aos quais estarão sujeitos (Jacobi, Günther, \& Giatti, 2012). 
No que se refere à participação da comunidade, a PNRH condiciona a integração da comunidade ao sistema de gestão hídrica mediante a constituição de organizações civis, de acordo com o artigo 48 (Brasil, 1997). Essa condicionante exige que a população seja um corpo social integrado, bem informado e proativo para o bom funcionamento do sistema de gestão. Para constituir essas entidades de representação, é necessário que os grupos se mobilizem e se organizem na defesa de seus interesses, pois não é possível a participação de forma individual nos espaços deliberativos (Fracalanza, Jacobi, \& Eça, 2013).

Dentro os princípios gerais da gestão hídrica na PNRH, tem-se a participação de "stakeholders" nos órgãos deliberativos, tendo estes, com o novo regramento, também sofrido modificações ao tornarem-se espaços descentralizados de tomada de decisão (Abers \& Keck, 2004).

Afirma-se que uma boa governança está atrelada ainda aos seguintes valores: responsabilidade, prestação de contas, transparência, equidade e justiça (Tortajada, 2010). Em especial, dá-se ênfase ao acesso à informação e à transparência como os aspectos centrais para o funcionamento de um sistema de gestão com participação simétrica entre as diversas categorias de atores envolvidos (Empinotti, Jacobi, \& Fracalanza, 2016). Nesse sentido, passa-se a identificar quais os mecanismos de promoção à participação da sociedade civil nos espaços deliberativos da política brasileira de gestão das águas.

\section{OS MECANISMOS DE PARTICIPAÇÃO DA SOCIEDADE CIVIL NA GESTÃO HÍDRICA}

A PNRH, inspirada no conceito de governança, instituiu dois mecanismos de gestão que oportunizam um ambiente de integração dos múltiplos atores nas tomadas de decisão sobre o destino das águas: os conselhos de recursos hídricos e os comitês de bacia hidrográfica. Contudo, alerta-se que, na escala local (ou seja, no âmbito municipal), esses mecanismos podem aumentar a transparência na relação sociedade-governo uma vez que promovem a aproximação entre eles; contudo, advertem também que, caso a sociedade não seja precavida quanto às ideologias do poder local, é possível que se intensifiquem mais arbitrariedades (Campos \& Fracalanza, 2010).

$\mathrm{Na}$ PNRH, é dito que tanto o conselho nacional como os estaduais de recursos hídricos, juntamente com os comitês de bacia hidrográfica, compõem o Sistema Nacional de Gerenciamento de Recursos Hídricos - SINGREH, conforme se vê no artigo 33 (Brasil, 1997), e que tais órgãos deliberativos devem conter representantes dos diversos usuários. $\mathrm{E}$, para que as organizações civis se integrem ao SINGREH, é exigido que sejam legalmente constituídas (artigo 48).

A exemplo do funcionamento do Conselho Nacional de Recursos Hídricos, no que consiste à participação da comunidade, faz-se necessária a sua organização em pessoas jurídicas sem fins lucrativos, tendo em seus estatutos um dos seguintes objetivos: defesa, preservação e conservação de recursos hídricos; promoção do desenvolvimento sustentável; produção e divulgação de informações e desenvolvimento de conhecimento e tecnologias para o uso racional de recursos hídricos; ou defesa de interesses difusos e coletivos da sociedade relacionados com recursos hídricos (IPEA, 2012). É somente mediante à formação de entidades de representação da comunidade que esse segmento poderá se habilitar em conselhos deliberativos. 
A participação dos múltiplos interessados nos espaços deliberativos é uma oportunidade de promover uma gestão colaborativa entre membros com interesses diferentes, mas com um comum objetivo: a busca pela solução de problemas hídricos. Ademais, esses espaços participativos permitem que os "stakeholders" emitam sugestões sobre a forma de implantação dos demais instrumentos de gestão previsto na PNRH, como a outorga de direito de uso da água, a cobrança pelo uso da água, os planos de recursos hídricos, entre outros, descentralizando o processo decisório e possibilitando a integração dos interesses dos setores menos favorecidos (Abers \& Keck, 2004).

Dentre os instrumentos da PNRH, têm-se os planos de recursos hídricos previsto no artigo 60 e 70 (Brasil, 1997). Esse instrumento é uma espécie de plano diretor de longo prazo no qual estarão descritos os programas e projetos planejados de forma integrada pelos "stakeholders" para determinada bacia hidrográfica, sendo fundamental a participação da comunidade nesse processo de negociação "sociotécnica", porque é este ator em especial que "vive e molda o território de uma bacia hidrográfica" (Machado, 2003b, p. 25). Logo, a PNRH prevê espaços participativos de gestão hídrica que, se bem explorados, proporcionará a inserção, inclusive, desses conhecimentos locais da população sobre os cursos d'água.

Pela perspectiva acima, o espaço participativo de apreciação, aprovação e acompanhamento dos planos de recursos hídricos é o Comitê de Bacia Hidrográfica, o qual é integrante do SINGREH, em conformidade com os artigos 33 e 38, da PNRH (Brasil, 1997). Os CBH's funcionam como "parlamentos das águas" visto que são órgãos colegiados compostos por representantes dos diversos tipos de interessados nos múltiplos usos da água e na sua preservação (Braga, Flecha, Pena, \& Kelman, 2008). Nesse aspecto, dentre as atribuições dos CBH's estão, ainda, a promoção do debate sobre as questões hídricas entre os atores, assim como a arbitragem administrativa dos conflitos entre eles, não podendo deixar de mencionar a sua competência para estabelecer os mecanismos de cobrança pelo uso da água e a sugestão de valores, conforme menciona o artigo 38, da PNRH (Brasil, 1997).

Outros espaços deliberativos abertos à sociedade civil e que também compõem o SINGREH são os Conselhos de Recursos Hídricos dos Estados e Distrito Federal, previstos no artigo 33, II, da PNRH (Brasil, 1997). Os CERH's são órgãos colegiados de tomada de decisão acerca dos quais o atual sistema de gestão hídrica promoveu a inclusão dos diversos atores interessados nos usos e conservação da qualidade da água como forma de dar legitimidade às decisões e, assim, garantir a implantação e eficiência no cumprimento (Porto \& Porto, 2008).

\section{METOdOLOGIA}

Trata-se de uma pesquisa exploratória uma vez que, com base no objetivo de investigar a efetividade da PNRH na Amazônia Legal sob o viés da participação da sociedade civil e do acesso à informação na atualidade, esse tipo de pesquisa permite se conhecer mais sobre a problemática. Ademais, o objetivo do presente estudo também comporta uma pesquisa descritiva por buscar identificar as relações entre essas variáveis (Gil, 2002).

No que se refere aos meios de execução desta pesquisa exploratória e descritiva, concretizou-se através de pesquisa bibliográfica e documental com o objetivo de aprimorar a familiaridade com o problema, bem como se utilizando de método estatístico para tratamento 
analítico dos dados (Medeiros \& Tomasi, 2016). Por esta perspectiva, este trabalho foi construído com base em artigos científicos publicados, prioritariamente, nos últimos sete anos em periódicos eletrônicos, dos quais foram extraídos o conceito de governança e a evolução de sua efetivação no âmbito das políticas ambiental e de recursos hídricos. Essas fontes de informação também serviram de base para averiguar de que forma está ocorrendo a participação da sociedade civil nos espaços democráticos de tomadas de decisão na gestão das águas.

A pesquisa documental foi realizada por meio de análise dos decretos de nomeação de conselheiros ou das atas dos Conselhos Estaduais de Recursos Hídricos (CERH's) dos estados da Amazônia Legal no sentido de identificar quais são os tipos de organizações que os compõem e qual a proporcionalidade entre os atores.

Com a finalidade de verificar as similaridades entre os estados amazônicos, foi aplicada uma estatística multivariada por meio do software Minitab 17. Para tanto, foram empregadas a análise de componentes principais (PCA) e a análise hierárquica de agrupamentos (HCA). A partir das componentes principais foi elaborado um gráfico de scores (observações). Para confirmar os resultados da PCA utilizou-se a HCA, por meio de um dendograma.

Outrossim, as informações disponibilizadas pelo Programa de Consolidação do Pacto Nacional pela Gestão das Águas (PROGESTÃO) no site oficial da Agência Nacional de Águas (ANA) foram fundamentais para demonstrar como está o processo de implantação dos instrumentos da $\mathrm{PNRH}$, com um enfoque especial naqueles que promovem a participação da comunidade na gestão de recursos hídricos dos estados da Amazônia Legal.

Explica-se que o estudo focou nos CERH's porque nem todos os estados brasileiros inseridos na Amazônia Legal possuem Comitês de Bacia Hidrográfica ( $\mathrm{CBH}^{\prime}$ 's) como será visto posteriormente. Portanto, a instância logo acima dos $\mathrm{CBH}^{\prime}$ s que possui espaço para a participação da sociedade civil são os CERH's. Importa salientar também que a pesquisa considerou como organização da sociedade civil as entidades de representação que os decretos de nomeação ou atas de reuniões assim as classificavam. Contudo, como alguns estados incluíam nesse grupo entidades técnicas, de ensino, de pesquisa ou profissional, como a Ordem dos Advogados do Brasil e o Conselho Regional de Engenharia e Agronomia, a pesquisa segregou-os em uma categoria em apartado a fim de visualizar somente as organizações representativas das comunidades.

\section{RESULTADOS E DISCUSSÃO}

Apesar de já ter se passado 20 anos de vigência da PNRH, a implementação de seus instrumentos de gestão ainda não foi concluída em todo o território nacional, especialmente nos estados da região amazônica, como se pode perceber na Tabela 1. Salientando-se que, na região Norte, todos os estados têm a outorga de direito de uso da água implementada; contudo, somente o Maranhão possui a cobrança pelo uso da água e apenas o Amazonas já realizou o enquadramento dos seus corpos hídricos (ANA, 2017).

Tabela 1: Estados brasileiros pertencentes à Amazônia Legal com Conselhos Estaduais de Recursos Hídricos, bem como o andamento da implantação de Comitês de Bacia Hidrográfica e de alguns instrumentos da Política

Nacional de Recursos Hídricos. 


\begin{tabular}{|c|c|c|c|c|}
\hline Estados & Conselhos Estaduais & $\begin{array}{c}\text { Comitês de Bacia } \\
\text { Hidrográfica }\end{array}$ & Planos Estaduais & $\begin{array}{c}\text { Sistema de } \\
\text { Informações }\end{array}$ \\
\hline AC & CEMACT/AC & Nenhum & Elaborado & Sim \\
\hline AP & CERH/AP & Nenhum & Elaborado & Sim \\
\hline AM & CERH/AM & 1 & Em elaboração & Não \\
\hline MA & CONERH/MA & 2 & Elaborado & Sim \\
\hline MT & CEHIDRO & 6 & Elaborado & Sim \\
\hline PA & CERH/PA & Nenhum elaborado & Sim \\
\hline RO & CRH/RO & 5 & Em elaboração & Sim \\
\hline RR & CERH/RR & Nenhum & Elaborado & Não \\
\hline TO & CERH/TO & 4 & Elaborado & Não \\
\hline
\end{tabular}

Fonte: ANA (2017), com adaptações. Elaboração dos autores.

Embora o cenário tenha mudado a partir da PNRH ao introduzir uma gestão mais democrática dos recursos hídricos, a Tabela 2 demonstra que, em se tratando da participação da sociedade nos espaços deliberativos, alguns estados da região amazônica apresentam poucas organizações representativas desses usuários em relação aos demais nos Conselhos Estaduais de Recursos Hídricos, conforme aferido em suas regulamentações.

Tabela 2: Estados brasileiros pertencentes à Amazônia Legal que implantaram o Conselho Estadual de Recursos Hídricos e o levantamento quantitativo das organizações participantes por tipo de usuário.

\begin{tabular}{|c|c|c|c|c|c|}
\hline Estados & $\begin{array}{l}\text { Poder } \\
\text { Público }\end{array}$ & $\begin{array}{l}\text { Usuários com } \\
\text { fins econômicos }\end{array}$ & $\begin{array}{l}\text { Sociedade } \\
\text { civil }\end{array}$ & $\begin{array}{c}\text { Instituições técnicas, de } \\
\text { pesquisa, de ensino ou } \\
\text { profissional }\end{array}$ & Instrumento normativo \\
\hline Acre & $12(63,3 \%)$ & $3(15,8 \%)$ & $3(15,8 \%)$ & $1(5,1 \%)$ & $\begin{array}{c}\text { Lei Estadual no. 1.022, } \\
\text { de } 21 \text { de janeiro de } \\
1992\end{array}$ \\
\hline Amapá & $20(74,1 \%)$ & $2(7,4 \%)$ & $3(11,1 \%)$ & $2(7,4 \%)$ & $\begin{array}{l}\text { Lei Estadual no. } 0686 \text {, } \\
\text { de } 07 \text { de junho de } 2002\end{array}$ \\
\hline Amazonas & $*$ & $*$ & $*$ & $*$ & $*$ \\
\hline Maranhão & $4(22,2 \%)$ & $6(33,3 \%)$ & $5(27,8 \%)$ & $3(16,7 \%)$ & $\begin{array}{c}\text { Decreto Estadual no. } \\
21.821, \text { de } 23 \text { de } \\
\text { dezembro de } 2005\end{array}$ \\
\hline $\begin{array}{l}\text { Mato } \\
\text { Grosso }\end{array}$ & $14(48,3 \%)$ & $10(34,5 \%)$ & $2(6,9 \%)$ & $3(10,3 \%)$ & $\begin{array}{c}\text { Decreto Estadual no. } \\
\text { 316, de } 06 \text { de } \\
\text { novembro de } 2015\end{array}$ \\
\hline Pará & $15(51,7 \%)$ & $7(24,2 \%)$ & $3(10,3 \%)$ & $4(13,8 \%)$ & $\begin{array}{c}\text { Decreto Estadual s/n, } \\
\text { de } 27 \text { de dezembro de } \\
2016\end{array}$ \\
\hline Rondônia & $*$ & $*$ & $*$ & $*$ & $*$ \\
\hline Roraima & $*$ & $*$ & $*$ & $*$ & $*$ \\
\hline Tocantins & $9(39,2 \%)$ & $8(34,8 \%)$ & $3(13,0 \%)$ & $3(13,0 \%)$ & $\begin{array}{l}\text { Ata da } 30 \text { a Reunião do } \\
\text { CERH/TO, de } 20 \text { de } \\
\text { março de } 2017\end{array}$ \\
\hline
\end{tabular}

Fonte: Decretos de nomeação, leis de criação dos Conselhos ou atas de reuniões dos participantes do conselho. Elaborado pelos autores. Nota: $\left({ }^{*}\right)$ Dados não disponíveis.

Verificou-se que a distribuição das vagas nos conselhos estaduais de recursos hídricos, geralmente, tem a seguinte característica: $40 \%$ das vagas são do poder público (União, estados e municípios); os outros $40 \%$ são destinados aos usuários da água com fins econômicos; e os $20 \%$ restantes ficam com os representantes da comunidade na forma de consórcios, associações, organizações técnicas ou de ensino, ONG's, etc. (Campos \& Fracalanza, 2010). Mas, diferentemente desta ótica, vislumbra-se na Tabela 2 que, em alguns dos órgãos colegiados 
estaduais de gestão de recursos hídricos amazônicos, há mais assentos ocupados pelo Poder Público, seguido por maioria representativa da sociedade civil (inserindo, aqui, as instituições técnicas, de pesquisa, de ensino ou profissional) e, por último, dos usuários com fins econômicos, como no Acre, Amapá e Maranhão.

Constata-se que, em regra geral, a composição dos conselhos estaduais de recursos hídricos reuni interesses políticos e econômicos ao destinar o quantitativo de vagas a esses setores de modo que, juntos chegam a $80 \%$ e, em relação à sociedade civil, resta apenas $20 \%$. Nessa mesma linha, Lopes (2002), ao analisar a composição do Conselho Estadual de Meio Ambiente do Pará, demonstrou a forte relação entre o poder econômico e político que, em regra, possuem maior possibilidade de articulação para aprovar tudo que seja de seus interesses, enquanto que a sociedade, embora possuísse assento no referido conselho, tinha um peso de pouca relevância nas decisões.

Analisando por esse prisma, esta pesquisa aponta um caminho que está sendo construído de forma diferente em alguns estados da Amazônia Legal (Acre, Amapá e Maranhão), porquanto a participação da sociedade nos conselhos já desponta em segundo lugar, quebrando o forte vínculo entre o político e o econômico.

Sabe-se que a distribuição das vagas para os stakeholders comporem os órgãos colegiados é o elemento que mais varia de uma gestão hídrica estadual para outra (Campos \& Fracalanza, 2010). E, diante desse fato, Jacobi (2002, p. 21) já alertava que, apesar de os conselhos serem espaços de participação de diversos segmentos, percebia-se a "dificuldade em assegurar uma composição efetivamente multi-setorial", porque ainda prevalece no Brasil uma "cultura política baseada na tutela e no controle" o que justifica a prevalência da representação governamental nos Conselhos.

Jacobi et al. (2012) indica outro fator para a pouca participação da sociedade civil, nos espaços deliberativos de gestão da água, seria o fato da PNRH ter dado mais valor aos corpos técnicos-científicos, concentrando estes o poder decisório devido aos seus conhecimentos produzidos e inibindo o maior envolvimento da comunidade. Em seguida, aponta sugestão para superar esta assimetria entre peritos e leigos, entre técnicos e usuários e entre setores público e privado, ao indicar o investimento em um processo de "aprendizagem social", ou seja, em atividades interdisciplinares e intersetoriais com o objetivo de aprimorar a interlocução entre os atores envolvidos, ampliando as suas responsabilidades e promovendo visões compartilhadas de gestão, que poderá, inclusive, limitar as ocorrências de abusos de poder ou prevalência de interesses econômicos ou políticos (Jacobi, 2010).

Nessa mesma linha, ressalta-se a importância da capacitação de formação de conselheiros da sociedade civil, bem como dos demais atores, a fim de que entendam as responsabilidade e finalidades das atividades assumidas com o cargo (Ramos, Cezare, Coutinho, Reis, \& Fernandes, 2012). Salienta-se que não basta apenas dispor de assento nos referidos conselhos, há que se ter uma formação para participar efetivamente dos mesmos, não apenas por tratar-se, no caso dos conselhos de recursos hídricos, de decisões sobre assuntos extremamente técnicos, mas, principalmente, para conhecerem como se dá o processo dessa participação e, a partir daí, poderem realizar uma articulação a fim de tornar sua participação mais efetiva.

Ademais, em que pese haja significativo quantitativo de representantes da sociedade civil integrando alguns CERH's dos estados amazônicos, pode-se inferir que a cidadania ativa ainda 
necessita de mais efetividade. Isso porque, conforme a Tabela 1, quatro estados ainda não têm CBH's implantados (Acre, Amapá, Pará e Roraima), e três estados ainda necessitam elaborar os seus Planos Estaduais de Recursos Hídricos (Amazonas, Pará e Roraima). Ademais, três estados apresentam-se sem a implantação do sistema de informações sobre recursos hídricos (Amazonas, Roraima e Tocantins). Como frisado anteriormente, o acesso à informação é a chave para a promoção da participação, tanto que a PNRH reconheceu esse viés ao incluir o referido sistema como um dos instrumentos da gestão hídrica no artigo 5, VI (Brasil, 1997).

A análise de componentes principais (PCA) foi empregada aos resultados provenientes da quantificação das organizações participantes por tipo de usuário em relação aos estados brasileiros pertencentes à Amazônia Legal que implantaram o CERH (dados da Tabela 2). Nesse sentido, utilizou-se uma matriz de $4 \times 6$, sendo 4 organizações participantes (variáveis) e 6 estados (observações). As duas primeiras componentes, PC1 e PC2, foram escolhidas por explicarem $86,8 \%$ da variação dos dados coletados. A Figura 1 apresenta o gráfico de scores (observações) da PCA dos 6 estados brasileiros que implantaram o CERH, na Amazônia.

Figura 1: Gráfico de scores (observações) da análise de componentes principais dos seis Estados brasileiros pertencentes à Amazônia que implantaram o CERH.

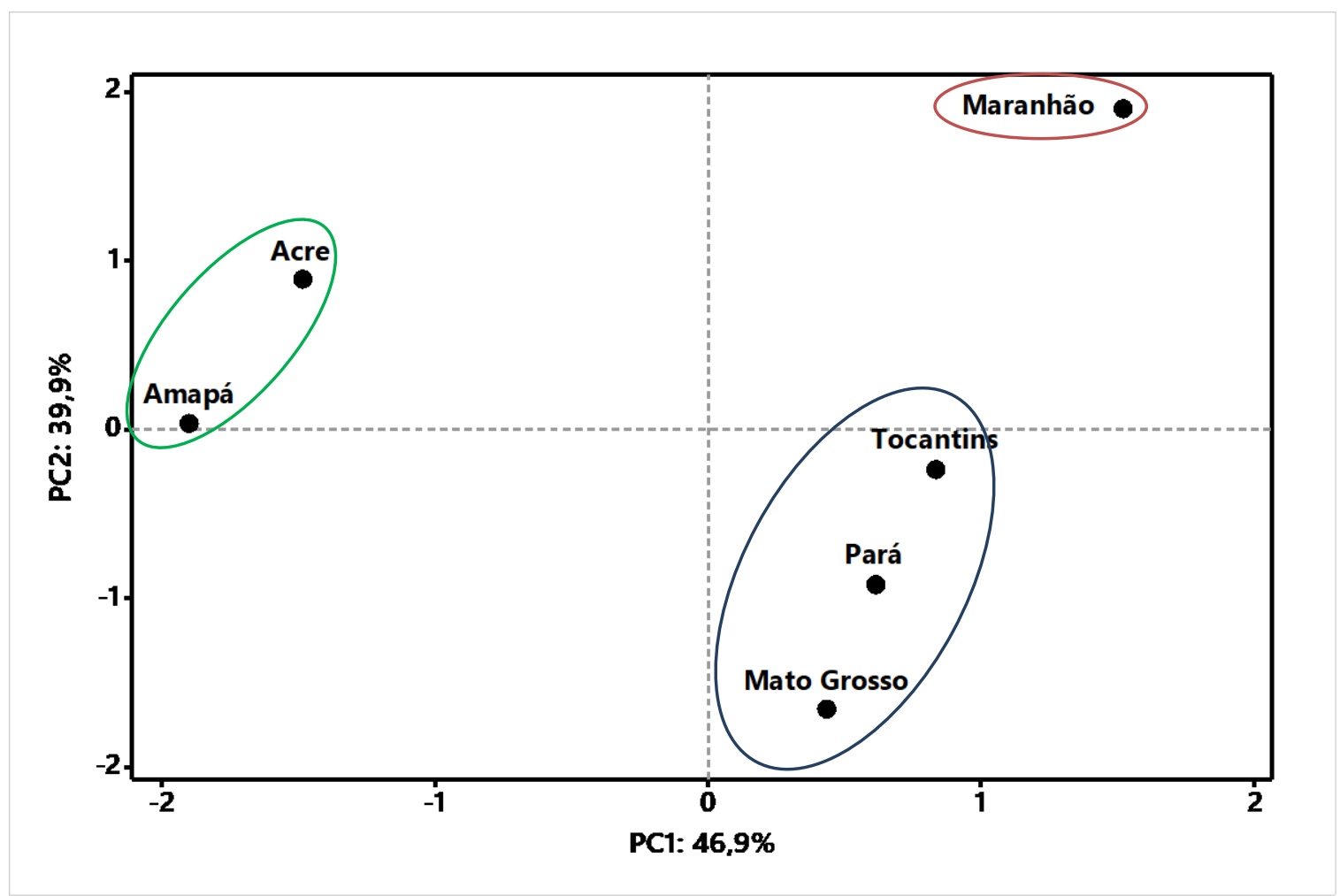

Fonte: Elaborado pelos autores.

A Figura 2 apresenta um dendograma relativo à análise hierárquica de agrupamentos (HCA) que foi aplicada para confirmar as correlações descritas na análise de componentes principais, conforme Figura 1. 
Figura 2: Dendograma da análise hierárquica de agrupamentos dos seis estados brasileiros pertencentes à Amazônia que implantaram o CERH.

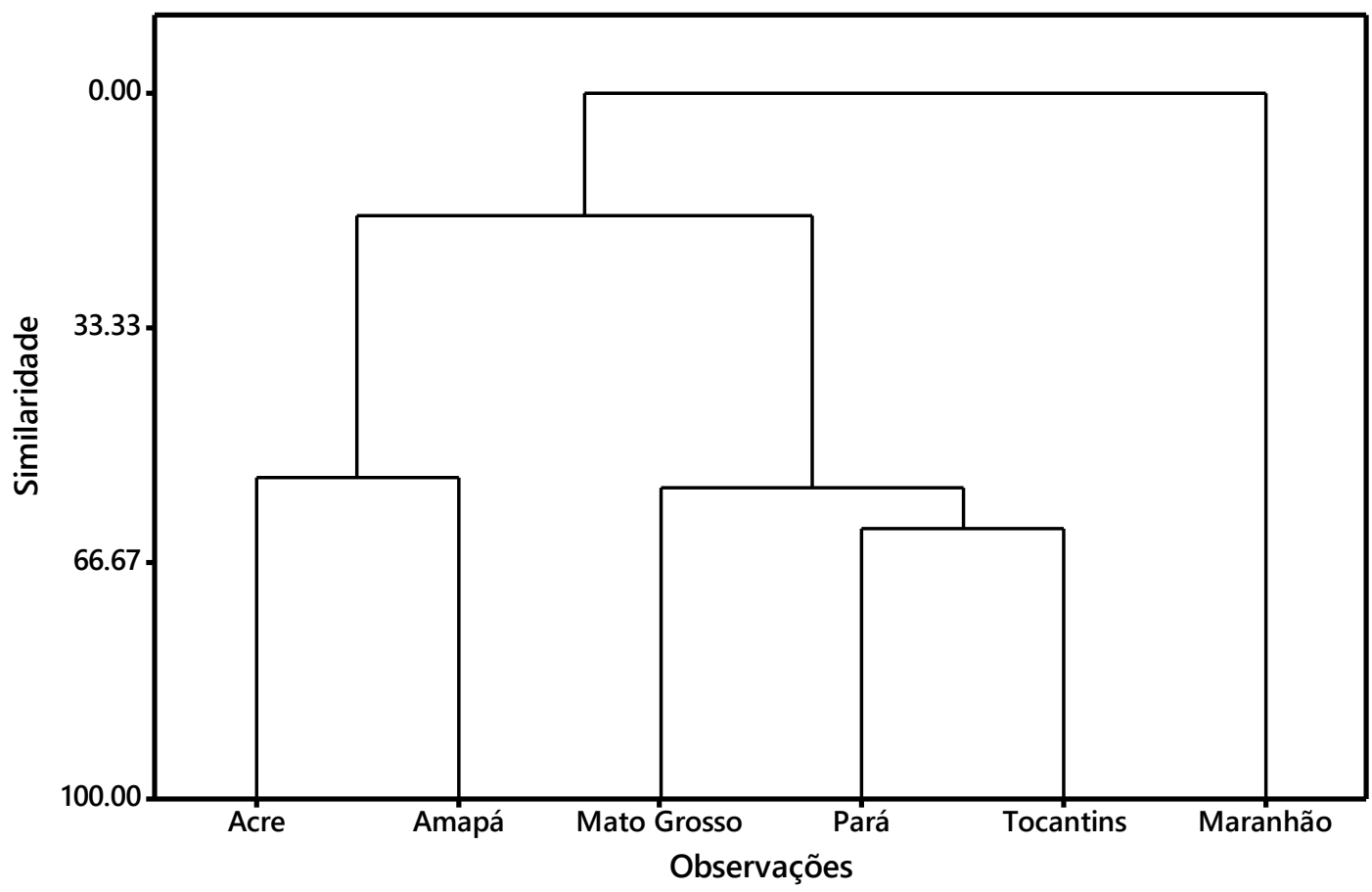

Fonte: Dados elaborados pelos autores.

De acordo com os resultados descritos no dendograma da Figura 2, constata-se que os dados levantados sobre o quantitativo das participações dos diversos atores nos seus respectivos CERH's permitiram agrupar, por similaridade, o Pará, o Tocantins e o Mato Grosso, em conformidade com a Figura 1. Fazendo uma análise associada com a Tabela 2, percebe-se que, nesse grupo, há prevalência de representatividade do Poder Público e dos usuários da água com finalidade econômica. Por outro lado, a semelhança entre o Amapá e o Acre está no fato de que mais de $60 \%$ das cadeiras nos seus conselhos estão ocupadas pelo Poder Público, demonstrando a necessidade de maior integração dos demais atores na gestão hídrica. O estado do Maranhão foi o que apresentou a organização do colegiado mais diferenciada devido ao menor quantitativo de entidades do Poder Público na gestão.

É interessante acentuar que o estado do Maranhão é o que se encontra com maior avanço em termos de implementação da PNRH na região da Amazônia Legal, pois somente resta a realização do instrumento enquadramento dos corpos de água em classes, de acordo com o quadro de metas da ANA (ANA, 2017). O referido estado já conseguiu implantar a cobrança pelo uso da água, a qual é vista pela literatura como o instrumento que mais encontra dificuldades de implantação devido aos diversos conflitos de interesses envolvidos (Souza, Drum, Teixeira, Godecke, \& Gonçalves, 2011; Campos \& Fracalanza, 2010).

A fim de "acompanhar a administração financeira dos recursos arrecadados com a cobrança" e desempenhar demais atividades de suporte ao CBH (artigo 44, da Lei da PNRH), de acordo com o Quadro de Metas do PROGESTÃO, o Maranhão também já possui Agência de Águas (Brasil, 1997; ANA, 2017). Cumprindo registrar que essa entidade funciona como uma secretaria 
executiva de apoio aos CBH's e integra o Sistema Nacional de Gerenciamento de Recursos Hídricos, conforme (Braga et al., 2008).

Em comparação com as demais regiões brasileiras, tem-se que a região da Amazônia Legal é aquela na qual a gestão hídrica virtualmente inexiste em conformidade com Veiga e Magrini (2013). As autoras afirmam que as regiões mais antropizadas, particularmente o Sudeste, e as regiões com maiores problemas de qualidade ou quantidade de água, como o Sul, Sudeste e Nordeste, são as que primeiramente envidaram esforços para implantar o modelo de gerenciamento hídrico. Contudo, alerta-se para a necessidade de se acelerar a implantação do sistema de gestão hídrica na região da Amazônia Legal a fim de que se aja preventivamente ao cenário de estresse hídrico causado pelas pressões de uso oriundas, especialmente, da expansão da fronteira agrícola e das atividades de mineração.

Embora haja agrupamento por similaridade de participações, os estados são bem diferenciados no que tange ao andamento da implementação dos instrumentos da PNRH como fora exposto na Tabela 1. Por exemplo, o Mato Grosso está mais avançado do que o Pará neste quesito, uma vez que aquele estado já possui o Plano Estadual de Recursos Hídricos elaborado e conta com seis CBH's, enquanto o Pará ainda não implementou nenhum desses instrumentos e o Tocantins somente possui $\mathrm{CBH}^{\prime}$ s. Sabe-se que a existência de $\mathrm{CBH}$ é importante para o andamento dos demais instrumentos de gestão hídrica, como o plano de recursos hídricos e a cobrança pelo uso da água, porque estes, teoricamente, devem ser elaborados de forma integrada com os diversos atores com o objetivo de se obter gestão democrática dos múltiplos usos (Abers, 2007).

Salienta-se que a efetividade dos conselhos está diretamente relacionada à paridade de composição, a qual, por vezes, é prevista formalmente, contudo, deixa a desejar na prática. Identifica-se que, geralmente, o Poder Público tem representantes mais bem informados pela facilidade de acesso às informações, com mais tempo disponível para dedicarem-se às atividades e contam com melhores recursos financeiros e materiais (Teixeira, 2005). Por outro lado, esse contexto ocorre inversamente quando se trata da representação da sociedade civil, tendo mais dificuldades para o desempenho do cargo. E o resultado dessa desigualdade é o reflexo negativo no processo de deliberação e na inovação nas políticas públicas (Tatagiba, 2005).

Por isso, Machado (2003a) reforça ser necessária a superação das distorções do acesso à informação, a construção de uma nova cultura política e, ainda, a mudança de comportamento do cidadão no sentido de tornar-se mais envolvido. Porque a simples implementação de uma nova política pública colegiada, integrada, descentralizada e participativa não é o bastante para promover a mudança social, ainda mais em uma sociedade cujo o modelo de política anterior concentrava as responsabilidades no Estado.

\section{CONCLUSÃO}

As análises dos dados levantados na presente pesquisa permitiram visualizar que ainda há muito o que ser feito para efetivar a PNRH de forma descentralizada nos estados brasileiros da Amazônia Legal, especialmente no que refere à promoção da participação da sociedade civil e ao acesso à informação. A simples previsão legal de espaços deliberativos paritários, por si só, não garante a concretude de uma boa governança hídrica. São necessários investimentos em 
atividades e programas de educação ambiental que sensibilizem, principalmente, os cidadãos quanto à importância do seu papel no andamento desta política pública de modo a sentirem-se parte integrante e responsável nos processos deliberativos quanto aos usos e preservação da água.

Aliado a isto, a disponibilização de informação e a facilitação de seu acesso aos interessados também são fatores fundamentais ao progresso do atual modelo de gestão hídrica brasileiro. Durante o desenvolvimento da pesquisa, foi difícil ter acesso a algumas informações sobre os Conselhos Estaduais de Recursos Hídricos e a implementação dos instrumentos de gestão da PNRH via rede mundial de computadores, especialmente, nos órgãos da esfera estadual e local, o que limitou a pesquisa a abordar somente o quantitativo de representantes dos diversos atores na composição dos CERH's.

Caso houvesse mais publicidade e facilidade de acesso às atas de reuniões em todos os CERH's, seria interessante verificar a frequência dos atores nas reuniões deliberativas, analisar os conteúdos das propostas levadas ao conselho, identificar de qual ator parte a maioria das propostas, entre outros aspectos. Estas são inclusive as sugestões para futuros estudos mais aprofundados sobre o andamento da PNRH nos estados da Amazônia Legal.

\section{REFERÊNCIAS}

Abers, R. N. (2007) Organizing for governance: building collaboration in Brazilian River Basins. World Development, 35(8), 1450-1463. Recuperado em 28 agosto, 2017, de http://www.sciencedirect.com/science/article/pii/S0305750X07000757

Abers, R. N., \& Keck, M. (2004) Comitê de bacia no Brasil: uma abordagem no estudo da participação social. Revista Brasileira de Estudos Urbanos e Regionais, 6(1), 55-68. Recuperado em 25 agosto, 2017, de http://repositorio.unb.br/handle/10482/21466

Aith, F. M. A., \& Rothbarth, R. (2015) O estatuto jurídico das águas no Brasil. Estudos Avançados, 163-177. Recuperado em 11 agosto, 2017, de http://www.scielo.br/scielo.php?script=sci_arttext\&pid=S0103-40142015000200163

Alves, E. L. (2013) Elementos de responsividade ambiental estatal no enfrentamento dos danos ambientais. In Silveira, C. E. M. da (Org.). Princípios de direito ambiental: articulações teóricas e aplicações práticas. Rio Grande do Sul: Educs. Recuperado em 4 setembro, 2017, de https://www.ucs.br/site/midia/arquivos/Principios_de_Direito_Ambiental.pdf

Agência Nacional de Águas. (2017). Programa de Consolidação do Pacto Nacional pela Gestão das Águas: panorama dos estados. Recuperado em 17 agosto, 2017, de http://progestao.ana.gov.br/portal/progestao/panorama-dos-estados

Braga, B. P. F., Flecha, R., Pena, D. S., \& Kelman, J. (2008) Pacto federativo e gestão de águas. Estudos Avançados, São Paulo, 22(63), 17-42. Recuperado em 2 setembro, 2017, de http://www.scielo.br/scielo.php?script=sci_arttext\&pid=S0103-40142008000200003

Brasil. Lei no. 9.433, de 8 de janeiro de 1997 (1997). Institui a Política Nacional de Recursos Hídricos, cria o Sistema Nacional de Gerenciamento de Recursos Hídricos, regulamenta o inciso XIX do art. 21 da Constituição Federal, e altera o art. 10 da Lei no 8.001, de 13 de março de 1990, que modificou a Lei no 7.990, de 28 de dezembro de 1989. Brasília: DOU de 9/1/1997. Recuperado em 26 dezembro, 2017, de http://www.planalto.gov.br/ccivil_03/leis/L9433.htm

Buriti, C. de O., \& Barbosa, E. M. (2014) Políticas públicas de recursos hídricos no Brasil: olhares 
sob uma perspectiva jurídica e histórico-ambiental. Revista Veredas do Direito, Belo Horizonte, 11(22), 225-254. Recuperado em 22 agosto, 2017, de http://www.domhelder.edu.br/revista/index.php/veredas/article/view/431

Camkin, J., \& Neto, S. (2016) Roles, rights, and responsabilities in water governance: reframing the water governance debate. World Affairs, 82-112. Recuperado em 31 agosto, 2017, de https://www.researchgate.net/publication/315918064_Roles_Rights_and_Responsibilities_i n_Water_Governance_Reframing_the_Water_Governance_Debate

Castro, F. do V. F. de, \& Alvarenga, L. J., \& Júnior, A. P. M. (2005) A Política Nacional de Recursos Hídricos e a gestão de conflitos em uma nova territorialidade. Geografias, Belo Horizonte, 37-50. Recuperado em 28 agosto, 2017, de http://www.igc.ufmg.br/portaldeperiodicos/index.php/geografias/article/view/331

Coletti, R. N. (2012) A participação da sociedade civil em instrumentos da política ambiental brasileira. Desenvolvimento e Meio Ambiente, Paraná, 39-51. Recuperado em 5 setembro, 2017, de http://revistas.ufpr.br/made/article/viewFile/25544/18572

Empinotti, V. L., Jacobi, P. R., \& Fracalanza, A. P. (2016) Transparência e a governança das águas. Estudos Avançados, 63-75. Recuperado em 13 agosto, 2017, de http://www.scielo.br/scielo.php?script=sci_arttext\&pid=S0103-40142016000300063

Fonseca, I. F. da, Bursztyn, M., \& Moura, A. M. M. de (2012) Conhecimentos técnicos, políticas públicas e participação: o caso do conselho nacional do meio ambiente. Rev. Sociol. Polít., Curitiba, 20(42), 183-198. Recuperado em 25 agosto, 2017, de http://www.scielo.br/scielo.php?script=sci_arttext\&pid=S0104-44782012000200013

Fracalanza, A. P., Jacob, A. M., \& Eça, R. F. (2013) Justiça ambiental e práticas de governança da água: (re)introduzindo questões de igualdade na agenda. Revista Ambiente \& Sociedade, São Paulo, 16(1), 19-38. Recuperado em 15 agosto, 2017, de http://www.scielo.br/pdf/asoc/v16n1/a03v16n1.pdf

Gil, A. C. (2002) Como elaborar projetos de pesquisa. 4. ed. São Paulo: Atlas.

Granziera, M. L. M. (2000) A cobrança pelo uso da água. Revista CEJ, Brasília, 1(12), 71-74. $\begin{array}{lllll}\text { Recuperado em } 26 & \text { agosto, de }\end{array}$ http://www.jf.jus.br/ojs2/index.php/revcej/article/viewArticle/362

Instituto de Pesquisa Econômica Aplicada - IPEA. (2012) O Conselho Nacional de Recursos Hídricos na Visão de seus Conselheiros: Relatório de Pesquisa Projeto Conselhos Nacionais: perfil e atuação dos conselheiros. Brasília: IPEA. Recuperado em 25 agosto, 2017, de http://www.ipea.gov.br/participacao/images/pdfs/relatoriosconselhos/120719_relatorio_re cursos_hidricos.pdf

Jacobi, P. R. (2003) Espaços públicos e práticas participativas na gestão do meio ambiente no Brasil. Revista Sociedade e Estado, Brasília, 18 (1-2), 315-338. Recuperado em 12 agosto, 2017, de http://www.scielo.br/scielo.php?script=sci_arttext\&pid=S010269922003000100015

Jacobi, P. R. (2002) O Brasil depois da Rio +10. Revista do Departamento de Geografia, São Paulo, 15(1), 19-29. Recuperado em 28 agosto, 2017, de http://www.geografia.fflch.usp.br/publicacoes/RDG/RDG_15/19-29.pdf

Jacobi, P. R. (2010) Aprendizagem social, desenvolvimento de plataformas de múltiplos atores e governança da água no Brasil. Revista Internacional Interdisciplinar Interthesis, Florianópolis, 7(1), 69-95. Recuperado em 26 agosto, 2017, de https://periodicos.ufsc.br/index.php/interthesis/article/view/1807-1384.2010v7n1p69 Jacobi, P. R., \& Barbi, F. (2007) Democracia e participação na gestão dos recursos hídricos no Brasil. Revista Katálysis, Florianópolis, 10(2), 237-244. Recuperado em 7 agosto, 2017, de 
http://www.scielo.br/scielo.php?script=sci_arttext\&pid=S1414-49802007000200012

Jacobi, P. R., Cibim, J., \& Leão, R. de S. (2015) Crise hídrica na macrometrópole paulista e respostas da sociedade civil. Estudos Avançados, 27-42. Recuperado em 12 agosto, 2017, de http://www.scielo.br/scielo.php?script=sci_arttext\&pid=S0103-40142015000200027

Jacobi, P. R., Fracalanza, A. P., \& Silva-Sánchez, S. (2015) Governança da água e inovação na política de recuperação de recursos hídricos na cidade de São Paulo. Revista Caderno Metrópole, São Paulo, 17(33), 61-81. Recuperado em 15 agosto, 2017, de http://www.scielo.br/pdf/cm/v17n33/2236-9996-cm-17-33-0061.pdf

Jacobi, P. R., Günther, W. M. R., \& Giatti, L. L. (2012) Agenda 21 e governança. Estudos Avançados, 331-340. Recuperado em 26 agosto, 2017, de http://www.scielo.br/pdf/ea/v26n74/a25v26n74.pdf

Lopes, S. R. M. (2002) Ação de controle sobre o licenciamento ambiental. In: Movendo idéias. Revista do Centro de Estudos Sociais Aplicados da UNAMA, Belém, 7(11).

Machado, C. J. S. (2003a) Recursos hídricos e cidadania no Brasil: limites, alternativas e desafios. Ambiente \& Sociedade, 6(2), 121-136. Recuperado em 18 agosto, 2017, de http://www.scielo.br/scielo.php?pid=S1414-

753X2003000300008\&script=sci_abstract\&tIng=pt

Machado, C. J. S. (2003b). Mudanças conceituais na administração pública do meio ambiente. Cienc. Cult., São Paulo, 55(4), 24-26. Recuperado em 2 setembro, 2017, de http://cienciaecultura.bvs.br/scielo.php?script=sci_arttext\&pid=S0009-67252003000400016

Matos, F., \& Dias, R. (2013). Governança da água e a gestão dos recursos hídricos: a formação de comitês de bacia no Brasil. Revista Desarrollo Local Sostenible, 6(17),1-13. Recuperado em 27 agosto, 2017, de http://www.eumed.net/rev/delos/17/governabilidade.pdf

Medeiros, J. B., \& Tomasi, C. (2016) Redação de artigos científicos: métodos de realização, seleção de periódicos, publicação. São Paulo: Atlas.

Miranda, R. G., Pereira, S. de F. P., Alves, D. T. V., \& Oliveira, G. R. F. (2009) Qualidade dos recursos hídricos da Amazônia - Rio Tapajós: avaliação de caso em relação aos elementos químicos e parâmetros físico-químicos. Ambi-Agua, Taubaté, 4(2), 75-92. Recuperado em 13 agosto, 2017, de www.ambi-agua.net/seer/index.php/ambiagua/article/download/210/pdf_288

Porto, M. F. A., \& Porto, R. L. L. (2008) Gestão de bacias hidrográficas. Estudos Avançados, 43-60. Recuperado em 5 setembro, 2017, de http://www.scielo.br/pdf/ea/v22n63/v22n63a04.pdf

Ramos, M. de F., Cezare, J. P., Coutinho, S. M. V., Reis, T. S., \& Fernandes, V. (2012) Conselhos setoriais: perfil dos conselheiros e sua influência na tomada de decisão. Revista Saúde e Sociedade, São Paulo, 21(3), 61-70. Recuperado em 30 agosto, 2017, de http://www.scielo.br/pdf/sausoc/v21s3/06.pdf

Santiago, D. P. A responsabilidade solidária do estado diante dos danos ambientais ocasionados por particulares e a efetividade dos princípios do direito ambiental. Revista de Filosofia do Direito, do Estado e da Sociedade, Natal, 3(2), 75-92. Recuperado em 4 setembro, 2017, de http://www.revistafides.com/ojs/index.php/br/article/view/329

Schmidt, J. J., \& Matthews, N. (2017) Global water governance: an overview. In: . Global challenges in water governance: environments, economies, societies. Suíca: Palgrave MacMillan Springer Nature. Recuperado em 18 agosto, 2017, de http://www.springer.com/gb/book/9783319615028

Souza, O. T. de, Drum, C. L., Teixeira, E. K., Godecke, M. V., \& Gonçalves, M. L. L. (2011) Instrumentos de política ambiental aplicáveis às águas: conflitos na cobrança pelo uso da água no Lago Guaíba. Ensaios FEE, Porto Alegre, 31(1), 807-836. Recuperado em 30 agosto, 
2017, de http://revistas.fee.tche.br/index.php/ensaios/article/view/2580

Tatagiba, L. (2005) Os conselhos gestores de políticas públicas e democracia participativa: aprofundando o debate. Revista Sociologia Política, Curitiba, 1(25), 209-213. Recuperado em 6 setembro, 2017, de http://www.scielo.br/pdf/rsocp/n25/31122.pdf

Teixeira, A. C. (2005) Formação dos conselhos no Brasil. In: Faria, H., Moreira, A., \& Versolato, Fernanda (Org.). Você quer um bom conselho? Conselhos municipais de cultura e cidadania cultura. São Paulo: Insitituto Pólis. Recuperado em 6 setembro, 2017, de http://webcache.googleusercontent.com/search?q=cache:cPs1vIRO-

8kJ:www.polis.org.br/uploads/1007/1007.pdf + cd $=2 \& \mathrm{hl}=\mathrm{pt}-\mathrm{BR} \& \mathrm{ct}=\mathrm{clnk} \& \mathrm{gl}=\mathrm{br}$

Tortajada, C. (2010) Water governance: some critical issues. International Journal of Water Resources Development, 297-307. Recuperado em 31 agosto, 2017, de https://www.researchgate.net/publication/248997410_Water_Governance_Some_Critical_I ssues

Tucci, C. E. M., Hespanhol, I., \& Netto, O. de M. C. (2001) Mecanismos de participação dos Usuários. In: . Gestão da água no Brasil. Brasília: Unesco. Recuperado em 23 agosto, 2017, de http://unesdoc.unesco.org/images/0012/001298/129870por.pdf

Tundisi, J. G. (2008) Recursos hídricos no futuro: problemas e soluções. Revista Estudos Avançados, 7-16. Recuperado em 10 agosto, 2017, de http://www.scielo.br/pdf/ea/v22n63/v22n63a02.pdf

Val, A. L., Almeida-Val, V. M. F. de, Fearnside, P. M., Santos, G. M. dos, Piedade, M. T. F., Junk, W. Novawa, S. R., Silva, S. T. da, \& Dantas, F. A. de C. (2010). Amazônia: Recursos hídricos e sustentabilidade. In: Tundisi, J. (ed.). Recursos Hídricos. São Paulo: Academia Brasileira de Ciências e Fundação de Amparo a Pesquisa do Estado de São Paulo.

Veiga, L. B. E., \& Magrini, A. (2013) The brazilian water resources management policy: fifteen years of success and challenges. Water Resour Manage, 27(7), 2287-2302. Recuperado em 9 junho, 2017, de https://link.springer.com/article/10.1007/s11269-013-0288-1

Water Governance Facility - WGF (2015) Water governance in perspective: Water Governance Facility 10 years - 2005-2010. Recuperado em 31 agosto, 2017, de http://watergovernance.org/resources/water-governance-in-perspective/

Wolkmer, M. de F. S., \& Pimmel, N. F. (2013) Política Nacional de Recursos Hídricos: governança da água e cidadania ambiental. Revista Sequencia, Florianópolis, 1(67), 165-198. Recuperado em 16 agosto, 2017, de http://www.scielo.br/pdf/seq/n67/07.pdf 